\title{
STRATEGI KABUPATEN SUMBAWA MENYIAPKAN SUMBER DAYA MANUSIA BERKUALITAS GUNA MENGHADAPI REVOLUSI INDUSTRI 4.0
}

\author{
Minten Ayu Larassati', Muammar Khadafie' ${ }^{2}$, Apriadi $^{3}$, \\ 1Program Studi Pendidikan Bahasa Inggris, Universitas Cordova \\ 2,3 Program Studi Ilmu Komunikasi, Universitas Teknologi Sumbawa \\ e-mail:mintenhijau@gmail.com
}

\begin{abstract}
The district government needs human research development to have quality and face industrial era 4.0. This is urgent, due to human resource development staff plays active role and dominant in every organizational activity. This research aims at identifying process and human research development strategies which has quality in facing industrial era 4.0. This qualitative descriptive research use documentation, interviews, and observation as collecting data method. Here are some strategies to achieve quality human resource development in order to be success in term of faster, easy, and efficient. Mastering technology, make digital innovation such as services system in application forms, planning policy for 2021. The process of establishing human resources is changing life patterns in line with industrial era 4.0. It is practicing education by guidance booklet need analysis. It is a planning roadmap for 2021. It is a practicing guidance booklet in line with the need of the industrial era of 4.0. the strategy and process of human resource development enhancement could be done maximally by the new year. It is when the vision and mission of government will be changed following 4.0 industrial era.
\end{abstract}

Keywords: human resource development, public service, revolution industry

Received: 30 November 2021

Accepted: 12 April 2021

Published: 28 Juni 2021

\section{PENDAHULUAN}

Saat ini Indonesia telah memasuki era industri 4.0. Perkembangan era ini membuat para pemimpin daerah ada di bawah tekanan kemajuan teknologi untuk membuat suatu inovasi yang baru agar pemerintah tidak ketinggalan zaman. Pemerintah daerah harus mulai mempersiapkan diri untuk mengembangkan sumber daya manusia (SDM) supaya mampu beradaptasi menghadapi revolusi industri 4.0. Sumber daya dan kemampuan organisasi merupakan basis bagi pembentukan keunggulan kompetitif secara terus-menerus. Dengan pandangan

Jurnal Pendidikan IImu Sosial, Vol. 31, No.1, Juni 2021,

p-ISSN: 1412-3835; e-ISSN: 2541-4569 
berbasis sumber daya tersebut diharapkan dapat mendukung keunggulan kompetitif melalui pengembangan kompetensi. Nilai masyarakat industri dan nilainilai masyarakat informasi belum tumbuh dan adaptif dalam kehidupan masyarakat, sementara nilai-nilai tradisi sudah berangsur ditinggalkan (Redjo, 2019). Para anggota organisasi yang memiliki kemampuan sesuai dengan persyaratan pekerjaan dapat meningkatkan daya saing organisasi dan dapat menyesuaikan diri dengan lingkungan yang dinamis (Wilson, 2012).

Revolusi industri 4.0 mengubah pandangan politik dan ekonomi dunia, dimana kemajuan industri menyebabkan hilangnya lapangan pekerjaan karena tergantikan oleh teknologi yang ada. Disisi yng lain, dengan adanya revolusi industri akan banyak kemudahan dan inovasi yang didapatkan dengan adanya dukungan teknologi digital (Rista, 2019). Hal ini dirasa penting karena SDM selalu berperan aktif dan dominan dalam setiap kegiatan organisasi, antara lain SDM menjadi perencana, pelaku, dan penentu terwujudnya tujuan organisasi. Agar suatu organisasi mampu terus bertahan dan bersaing, dominasi teknologi saja tidak cukup jika tidak ditunjang oleh sumber daya manusia yang unggul. SDM dalam suatu organisasi dapat diandalkan untuk menggerakkan sumber daya lainnya dalam mewujudkan tujuan bersama. SDM yang dibutuhkan organisasi adalah SDM yang sanggup menguasai teknologi dengan cepat, adaptif, responsif, terhadap perubahanperubahan teknologi dan memiliki sikap melayani serta berintegritas tinggi. Rohida (2018) menyatakan bahwa diperlukan peningkatan keterampilan atau upskilling dan pembaruan keterampilan atau re-skilling terhadap SDM untuk benarbenar dapat berkompeten.

Presiden Joko Widodo menyatakan pembangunan bangsa tidak mungkin bisa maju bila mengandalkan reformasi kelembagaan tanpa mereformasi pola pikir manusia atau sikap dari orang-orang yang menjalankan sistem (Kompas, 2014). Dalam ungkapan tersebut presiden menyadari bahwa pembangunan ekonomi Indonesia terletak pada kemampuan masyarakat untuk mengubah pola pikir, sikap dan perilaku guna memperbaiki kelemahan struktural dan ekonomi. Mereformasi pola pikir manusia salah satunya dengan meningkatkan SDM, ini suatu keharusan dalam rangka membangun perekonomian suatu daerah di era industri 4.0.

Betapa pentingnya SDM dalam menghadapi era industri 4.0, sehingga mendorong pemerintah daerah Kabupaten Sumbawa bersegera menyiapkan sumber daya manusia berkualitas dan memiliki bakat tinggi. Peningkatan daya saing SDM merupakan topik yang menarik untuk dikaji dan dibicarakan termasuk dalam rangka mempersiapkan diri menjalankan era industri 4.0. Pemerintah telah mengoptimalkan tiga pilar percepatan peningkatan kompetensi sumber daya manusia, tiga pilar tersebut mengacu pada penyiapan SDM yang sesuai dengan kebutuhan dunia industri baik dari segi kualitas maupun kuantitas. Ketiga komponen tersebut menjadi dasar bagi seluruh pemangku kepentingan, agar pembangunan SDM kompeten ini sejalan dengan semangat pemerataan pembangunan ekonomi (Safri, 2016).

Jurnal Pendidikan IImu Sosial, Vol. 31, No.1, Juni 2021, 
Dengan latar belakang tersebut peneliti tertarik mengkaji mengenai strategi Kabupaten Sumbawa dalam menyiapkan sumber daya manusia berkualitas guna menghadapi revolusi industri 4.0. Topik ini dirasa penting karena sumber daya manusia Kabupaten Sumbawa kedepannya harus sudah mampu mengikuti tantanan global. Ibrahim et al, (2018) pernah melakukan kajian terhadap dampak program pengembangan SDM melalui pelatihan keterampilan pada pemuda di Sumbawa Barat dan menghasilkan analisis potensi yang bernilai ekonomis dan potensial.

\section{METODE PENELITIAN}

Dalam penelitian ini pendekatan yang digunakan adalah pendekatan kualitatif dengan metode deskriptif. Menurut Creswell (2013) penelitian kualitatif merupakan metode-metode untuk memahami makna dan mengeksplorasi hal-hal yang berasal dari masalah-masalah sosial, Adapun prosesnya yaitu mengajukan pertanyaan, mengumpulkan data yan spesifik dari partisipan, dan menganalisis data secara induktif. Sementara itu, metode yang dipilih metode deskriprif, yaitu mendeskripsikan tentang strategi kabupaten sumbawa dalam meningkatkan kualitas sumberdaya manusia guna menghadapi era revolusi industri 4.0. Adapun fokus penelitian ini adalah mengidentifikasi arah kebijakan dan strategi kabupaten sumbawa dalam meningkatkan kualitas sumberdaya manusia di era revolusi industri 4.0. Pemilihan informan dilakukan secara sengaja berdasarkan kriteria yang telah ditentukan berdasarkan dari tujuan penelitian ini. Maka adapun informan yang ditentukan adalah Badan Kepegawaian Daerah kabupaten Sumbawa, Dinas/OPD yang ikut menyusun dan menjalankan program yang memiliki sasaran dan tujuan searah dengan arah kebijakan pembangunan kabuaten Sumbawa dalam meningkatkan kualitas sumberdaya manusia dalam upaya menghadapi era revolusi industri 4.0.

Penelitian ini dilakukan di kabupaten Sumbawa, terutama di dinas-dinas yang terkait yang menjalankan dan menyusun program yang sasaran dan tujuannya mengarah atau sejalan dengan arah kebijakan pembangunan pemerintah daerah kabupaten Sumbawa dalam meningkatkan kualitas sumber daya manusia dalam upaya menghadapi era revolusi industri 4.0. Dalam mengumpulkan data penelitian, peneliti menggunakan atau memilih teknik pengumpulan data yaitu; Pertama, observasi lapangan, peneliti melakukan pengamatan langsung di lokasi penelitian, pencatatan data dilakukan secara terstruktur maupun semi terstruktur. Kedua, wawancara mendalam, yaitu percakapan dengan maksud dan tujuan tertentu, pertanyaanpertanyaan yang diajukan bersifat tidak terstruktur dan terbuka agar memunculkan pandangan opini dari partisipan. Ketiga, studi pustaka, teknik pengumpulkan data dengan menggunakan dokumen-dokumen sebagai sumber data, seperti perundang undangan, peraturan pemerintah daerah, peraturan bupati dan sebagainya yang memiliki relevansi dan keterkaitan dengan penelitian ini. Data-data yang telah diteliti akan dianalisis dengan metode

Jurnal Pendidikan IImu Sosial, Vol. 31, No.1, Juni 2021, 
deskriptif kualitatif. Dalam menganalisis data digunakan cara atau tahap secara berurutan, terdiri dari tiga alur kegiatan yaitu: pengumpulan data sekaligus reduksi data, penyajian data, dan penarikan kesimpulan atau verifikasi (Creswell, 2013).

\section{HASIL PENELITIAN DAN PEMBAHASAN}

Strategi Pemerintah Daerah Kabupaten Sumbawa Guna Mewujudkan SDM Kabupaten Sumbawa yang Berkualitas di Era Industri 4.0

Kabupaten Sumbawa saat ini berada pada tahap awal revolusi industri 4.0 yang baru mulai merubah cara bekerja, cara hidup, dan cara berkomunikasi. Revolusi mengakibatkan transformasi yang sangat berbeda dengan pola sebelumnya, sehingga perlu direspon oleh pemangku kepentingan. Badan Kepegawaian Pendidikan dan Pelatihan (dahulunya BKD kini BKPP) `sepakat bahwa perangkat pemerintah daerah harus merespon revolusi industri 4.0 agar pelayanan lebih Cepat, Mudah dan Singkat. Melihat karakteristik dari revolusi industri 4.0 yang didefinisikan sebagai perubahan yang revolusioner berbasiskan berbagai teknologi memaksa kabupaten Sumbawa harus menyusun strategi agar SDM memiliki kompetensi yang berkualitas. Kedepannya perangkat daerah harus menyesuaikan dengan munculnya cyber physical-system, internet of thing (IoT), big data, dan aneka layanan memanfaatkan IT, agar perubahan revolusioner yang terjadi ketika teknologi Informasi diterapkan pada semua lini tenaga aparatur daerah telah menguasai.

Sebagai perpanjangan tangan pemerintah pusat, Kabupaten Sumbawa harus merespon dan menyesuaikan perubahan yang revolusioner ini agar mampu memberikan pelayanan yang semakin efisien. Pelayanan terhadap masyarakat merupakan aspek yang penting utamanya pada pelayanan berbasis elektronik baik dalam bidang pemerintahan maupun swasta (Mahsyar, 2011; Hareva \& Legowo, 2017). Kabupaten Sumbawa yang secara administrative terdiri dari 24 kecamatan jika tidak menyambut era industri 4.0 yang berbasiskan IT dkhawatirkan akan kesulitan, sehingga perlu berinovasi dan memiliki komitmen untuk menjadikan Indonesia semakin maju. Adaptasi terhadap perubahan era digital di Sumbawa tentunya adalah merubah mental SDMnya sehingga dapat melakukan inovasi. Wujud program-program nyata yang telah dilakukan dan yang oleh BKPP dalam merespon revolusi industri 4.0 menyiapkan aplikasi-aplikasi seperti Siap Pangkat (untuk pengurusan pangkat) disiplin untuk presensi dan kinerja dan sistem informasi kepegawaian (SIMPEGDA).

\section{Proses Pembentukan SDM Kabupaten Sumbawa yang Berkualitas di Era Industri 4.0}

Dari sudut pandang pemerintah, era industri 4.0 membawa harapan dan tantangan. Harapan tersebut adalah adanya peluang efisiensi dan produktivitas yang akan membuka pasar baru dan pertumbuhan ekonomi. Pada saat bersamaan, revolusi ini menimbulkan tantangan khususnya disrupsi SDM. Keuntungan terbesar

Jurnal Pendidikan IImu Sosial, Vol. 31, No.1, Juni 2021,

p-ISSN: 1412-3835; e-ISSN: 2541-4569 
bahwa era Industri 4.0 mempunyai kemampuan untuk mengadaptasi dalam meningkatkan kualitas hidup, SDM dapat bekerja lebih baik, waktu yang sedikit, kebutuhan dapat disediakan secara efisien dalam platform digital. Dengan demikian semua pekerjaan rutin yang mengandalkan catatan manual akan berkurang dan berganti, di sini peran SDM dalam pemerintahan akan berhubungan dengan aktivitas audit, berinovasi dan berfikir kritis sehingga pembentukan SDM yang berkualitas harus diarahkan.

SDM di Kabupaten Sumbawa dalam hal ini direpresentasikan BKPP diarahkan untuk berubah pola hidup sesuai gaya revolusi industri 4.0, apalagi karena saat ini terjadi pademi Covid-19, sehingga kegiatan sehari-hari sudah melakukan digitalisasi, memaksimalkan penggunaan IT dan internet of thing, hingga rapat sudah menggunakan portal digital seperti Zoom Meeting dan Google Meet. Sehingga dengan adanya Covid-19 SDM sudah menyesuaikan dan memasuki digitalisasi.

Setidaknya terdapat tiga peran dasar teknologi yang bisa dijadikan dasar BKPP dalam mengidentifikasi untuk membentuk SDM yang berkualitas di era industri 4.0, respon terhadap revolusi dalam serial teknologi. pertama; Substitute, dimana teknologi mampu menggantikan sepenuhnya fungsi manusia dengan manampilkan aktivitas yang lebih efisien dan produktif, kedua; Integrator, dimana teknologi merupakan bagian dari aktivitas bekerja manusia, dalam rangka meningkatkan kualitas aksi tanpa mengganti kehadiran manusia itu sendiri, ketiga; Mediator, dimana teknologi adalah platform dalam memediasi kehidupan manusia dari isu personal ke hubungan sosial.

Dalam rencana tahunan ke depannya BKPP akan dilakukan pendidikan agar SDM mampu memainkan peran di era revolusi industri, yakni; pertama, yang dilakukan adalah melakukan analisis kebutuhan diklat, disini BKPP akan berusaha membentuk tim yang kompeten untuk menyusun analisis kebutuhan diklat yang sesuai dengan kebutuhan era digital. Diklat harus disusun berdasar kebutuhan masing-masing unit karena disetiap unit yang berbeda memilki karakteristik yang berbeda pula baik secara tugas maupun fungsinya (Ngindana \& Hermawan, 2019). Kedua, saat ini BKPP telah berproses dalam membuat roadmap tahunan untuk tahun 2021 dan sudah menyesuaikan perubahan era Industri 4.0 dan harus sesuai regulasi. Untuk saat ini tidak dapat langsung di lakukan karena belum adanya perintah atau Surat Keputusan (SK) yang turun. BKPP sendiri sudah mempersiapkan dan sudah banyak yang di lakukan untuk menuju ke perubahan Era Industri 4.0. Ketiga, diklat-diklat seperti diklat kepemimpinan, pra-jabatan juga diklat fungsional yang mencakup pendidikan, dinas kesehatan dan banyak instansi lainnya juga akan diarahkan sesuai dengan perubahan era industri 4.0.

Berkaitan dengan sasaran-sasaran dan tujuaan yang akan dicapai BKPP dalam mempersiapkan SDM Aparatur Sipil Negara (ASN) yang berkualitas. BKPP melihat dan meninjau indeks profesionalitas SDM untuk diukur sampai dimana kualitas SDM ASN di Kabupaten Sumbawa, dan saat ini indeksnya masih rendah, sehingga sarannya yaitu pertama dari instansi-instansi pemerintahan khususnya

Jurnal Pendidikan IImu Sosial, Vol. 31, No.1, Juni 2021,

p-ISSN: 1412-3835; e-ISSN: 2541-4569 
bidang jasa, seperti pendidikan dan kesehatan. Kedua bidang ini yang langsung berhadapan dengan masyarakat. Di Kabupaten Sumbawa ini masih belum maju, sehingga perlu melakukan kajian banding untuk Sumbawa menjadi lebih baik dan siap untuk revolusi industri 4.0 ini. Misalnya, daerah Lombok Timur yang dinilai lebih maju, maka minimal Kabupaten Sumbawa ke depannya sama majunya dan BKPP sedang mempersiapkan seperti daerah-daerah lain. Dengan mempersiapkan diklat SDM yang berkualitas sesuai dengan industri 4.0 dan memberikan pengertian pada masyarakat akan kebutuhan teknologi dan kemudahan teknologi kedepannya BKPP akan mempersiapkan SDM yang berkualitas. Diklat, pendidikan dan pelatihan pegawai dapat mengembangkan atau meningkatkan kompetensi pengetahuan, keterampilan, dan sikap aparatur dalam melaksanakan tugas dan jabatan (Samad et al., 2015). Penelitian lain dari Dharta (2010) membuktikan bahwa diklat dapat meningkatkan kinerja pegawai. Karena sekarang berada di penghujung tahun dekade kepemimpinan Bupati yang mana visi misi beliau memang belum mengarah ke sana jadi mungkin setelah pergantian nanti visi misi Bupati pasti akan merujuk ke revolusi industi 4.0 ini dan akan lebih memudahkan BKPP untuk mengaplikasikan apa yang sudah di rencana dalam roadmap tahun 2021. Kabupaten Sumbawa harus segera berbenah menyiapkan SDM yang berkualitas dalam menghadapi era industri 4.0.

\section{KESIMPULAN}

Strategi pemerintah daerah Kabupaten Sumbawa guna mewujudkan SDM kabupaten sumbawa yang berkualitas di era industri 4.0 adalah pertama, memperbaiki pelayanan BKPP bersepakat bahwa perangkat pemerintah daerah harus merespon revolusi industri 4.0 agar pelayanan lebih Cepat, Mudah dan Singkat. Kedua, penguasaan terhadap teknologi itu sendiri, kedepannya perangkat daerah harus menyesuaikan dengan munculnya cyber physical-system, internet of thing (IoT), big data, dan aneka layanan memanfaatkan IT agar ketika diterapkan SDM telah menguasai. Ketiga, inovasi sistem digital, Keberadaan sistem secara digital BKPP dalam merespon revolusi industri 4.0 menyiapkan aplikasi-aplikasi seperti Siap Pangkat (untuk pengurusan pangkat), E-disiplin untuk presensi dan kinerja, SIMPEGDA (sistem informasi kepegawaian). Keempat, merumuskan kebijakan untuk mewujudkan SDM berkualitas, Sangat merespon revolusi industri 4.0 , Karena mengikuti kebijakan selama satu tahun ini yakni kebijakan tahun 2020, jadi perintah hanya mengadakan kebijakan pelayanan melalui inovasi aplikasi tadi, dan ke depannya BKPP yang merupakan tempat pembentukan SDM di Kabupaten Sumbawa tahun depan 2021 akan mengusahakan untuk perencanaan.

Proses Pembentukan SDM di Kabupaten Sumbawa yang berkualitas di era industri 4.0 adalah pertama merubah pola hidup SDM di Kabupaten Sumbawa dalam hal ini direpresentasikan BKPP diarahkan untuk berubah pola hidup sesui gaya revolusi industri 4.0, apalagi karena saat ini terjadi pandemi Covid-19, Sehingga

Jurnal Pendidikan IImu Sosial, Vol. 31, No.1, Juni 2021, 
dengan adanya Covid-19 SDM sudah menyesuaikan dan memasuki digitalisasi. Kedua, pendidikan untuk SDM di Sumbawa langkah yang dilakukan ada tiga yakni (a) melakukan analisis kebutuhan diklat, (b) berproses dalam membuat roadmap tahunan untuk tahun 2021 dan sudah direncanakan dibuat untuk menyesuaikan perubahan era Industri 4.0 dan harus sesuai regulasi. (c) diklat-diklat seperti diklat kepemimpinan, pra-jabatan juga diklat fungsional yang mencakup pendidikan, dinas kesehatan dan banyak instansi lainnya akan diarahkan sesuai dengan perubahan era industri 4.0, Ketiga, instansi yang diutamakan untuk membentuk SDM yang berkualitas ke depannya adalah bidang jasa seperti instansi pendidikan dan kesehatan. Sekarang berada di penghujung kepemimpinan Bupati yang mana visi misinya belum mengarah ke era Industri 4.0, mungkin setelah pergantian keapemimpinan akan merujuk ke revolusi industi 4.0, dan akan lebih memudahkan BKPP untuk rencana dalam roadmap tahun 2021.

\section{DAFTAR PUSTAKA}

Creswell, J. W. 2013. Research Design Pendekatan Kualitatif, Kuantitatif dan Mixed, Edisi III. Yogyakarta: Pustaka Pelajar.

Dharta, I. K. 2010. Pengaruh Pendidikan dan Pelatihan (Diklat) Terhadap Kinerja Pegawai Negeri Sipil Pada Sekretariat Daerah Kota Malang. Jurnal Ekonomi Modernisasi, 6(2), 140-160.

Hareva, K. R. P., \& Legowo, N. 2017. The Governance Measurements of Information System Using Framework COBIT 5 in Automotive Company. Journal of Chemical Information and Modeling, 53(9), 1689-1699.

Ibrahim, Kamaluddin, Mas'ad \& Junadi, A.M. 2018. Peningkatan Kualitas Sumber Daya Manusia Pemuda Pesisir Melalui Pelatihan Manajemen Kepemimpinan di Kecamatan Poto Tano Kabupaten Sumbawa Barat. Selaparang: Jurnal Pengabdian Masyarakat Berkemajuan, 2(1), 43-47.

Kompas. 2014. Jokowi dan Arti Revolusi Mental. Diakses dari https://nasional.kompas.com/read/2014/10/17/22373441/Jokowi.dan.Art i.Revolusi.Mental.?pge=all

Mahsyar, A. 2011. Masalah Pelayanan Publik Di Indonesia Dalam Perspektif Administrasi Publik. OTORITAS: Jurnal Ilmu Pemerintahan, 1(2), 81-90. 
Ngindana, R., \& Hermawan, R. 2019. Analisis Kebutuhan Diklat Pegawai Negeri Sipil Berbasis Kesenjangan Kerja Unit Kerja di Lingkungan Pemerintah Kota Mojokerto. Jurnal inovasi Ilmu Sosial dan Politik. 1(1), 1-11.

Redjo, S.I. 2019. Pemerintahan yang Cerdas yang Dibutuhkan dalam Revolusi Industri 4.0. Jurnal Ilmu Politik dan Komunikasi. 9(1), 1-7.

Rista, D. 2019. Strategi Pemerintah Dalam Menghadapi Revolusi Industri 4.0: HAKI. OSF Preprint. 1-8.. https://doi.org/10.31219/osf.io/c3vbj

Rohida, L. 2018. Pengaruh Era Revolusi Industri 4.0 terhadap Kompetensi Sumber Daya Manusia. Jurnal Manajemen Bisnis Indonesia, 6(1), 114-136.

Safri, H. 2016. Pengembangan Sumber Daya Manusia Dalam Pembangunan. Journal of Islamic Education Management, 1(1), 102-112.

Samad, F. H., Pankey, M., \& Rompas, S. 2015. Efektivitas Pendidikan Dan Pelatihan Pegawai Negeri Sipil Dalam Meningkatkan Kinerja Aparatur. Jurnal Administrasi Publik. 4(32), 1-8.

Wilson, B. 2012. Manajemen Sumber Daya Manusia. Jakarta: Erlangga. 